\title{
How Should We Talk About Corporations? The Languages of Economics and of Citizenship
}

\author{
James Boyd White
}

My immediate subject in this Comment is section 2.01 of the American Law Institute's proposed Principles of Corporate Governance (Tentative Draft No. 2), which defines in general terms the proper objectives and conduct of a business corporation. ${ }^{1}$ My larger subject has to do with the adequacy and inadequacy of various languages in which corporate purposes and limits might be expressed, and especially with the limits of the economic language used in the ALI Draft.

The section on corporate purpose was heatedly debated at the ALI meeting last spring and will presumably be discussed again. ${ }^{2}$ As readers of the Journal may already know, the corporate governance project as a whole is one of the most pressing and problematic on the Institute's agenda, and section 2.01 is crucial to the meaning of the current Draft. While I have not practiced corporate law for many years, I have recently done some thinking about writing and argument, and it is in that light that I wish to offer these remarks. Of course, I will talk about the substance of corporate law, and to some extent what I say will differ from the Tentative Draft. But I think that much of what I say on the merits is at

$\dagger$ Professor of Law and Professor of English Language and Literature, The University of Michigan. I wish to thank Alfred Conard, Melvin Eisenberg, Judith Lachman, Michael Rosenzweig, Terrance Sandalow, Joseph Sax, Joseph Vining, Ghristina Whitman, John White, and Michelle White for helpful comments on this Comment. Of course, none of them is responsible for the views expressed in it and some disagree strongly with what I say.

1. Principles of Corporate Governance: Analysis and Recommendations $\$ 2.01$ (Tent. Draft No. 2, April 13, 1984) [hereinafter cited as Draft]:

The Objective and Conduct of the Business Corporation.

A business corporation should have as its objective the conduct of business activities with a view to enhancing corporate profit and shareholder gain, except that, whether or not corporate profit and shareholder gain are thereby enhanced, the corporation, in the conduct of its business

(a) is obliged, to the same extent as a natural person, to act within the boundaries set by law,

(b) may take into account ethical considerations that are reasonably regarded as appropriate to the responsible conduct of business, and

(c) may devote a reasonable amount of resources to public welfare, humanitarian, educational, and philanthropic purposes.

2. The American Law Institute will continue its consideration of the Principles of Corporate Governance at its Annual Meeting in Washington D.C. on May 14-15, 1985. 
some level shared by the drafters; at least in their commentary I see intimations of views similar to my own, and to the extent this is true, the difficulty of the Draft from my point of view lies less in the drafters' underlying conception of the corporation and its role in the world than in the way that conception is expressed in the language of the section.

On that point, I think that the language of section 2.01 creates a false opposition between the economic goals of a corporation (expressed as an ultimately self-interested duty to enhance "corporate profit and shareholder gain") and certain other corporate aims or activities, which are conceived of as public-spirited or philanthropic (including its obligation to obey the law). This opposition is, I think, inconsistent with the basic conception of the corporation expressed in the best tradition of American corporate law and practice. What is worse, it invites thought and discussion of a clashing and unproductive kind about these important matters.

This is in fact the kind of discussion that took place at the annual meeting of the ALI last spring. Speakers for the most part took the view either that the sole purpose of the corporation was to make money for its shareholders, or that the corporation had social obligations in addition to, and inconsistent with, that purpose. Little content was given to these two positions, which seemed to share, in addition to their simplicity, the assumptions that there were only these two positions and that the task of the Institute was to choose between them.

These seem to me to be false assumptions. They led the members of the Institute to perform below their usual high standard and may lead the Institute itself to take an unfortunate position on this important matter.

\section{I.}

It is easy enough to imagine how the Draft came to its present form. For people in our intellectual culture, it is second nature to conceive of institutions in terms of their purposes, which are thought to provide substantive criteria for shaping and judging action. One purpose of any business is obviously to make money. The question thus arises whether it shall have any other purposes, and we find ourselves debating simplicities of the sort observed at the meeting.

But I think that it is a mistake for the Draft to try to reduce the nature and aspirations of a business corporation to any such statement of "purposes" and especially to oppose "selfish" and "altruistic" purposes in this simple way. This opposition is false to our experience and may introduce a dangerous ideology into our law.

Consider the way in which American businesses have traditionally behaved. A bank in a small or medium-sized city does not decide whether to lend money to a borrower simply on the ground of the rate and security of 
return, but (as some of the comments to section 2.01 themselves make plain) properly takes into account the effect that the enterprise to be supported by the loan will have on the community as a whole, over the long as well as the short term. Similarly, those who manage a manufacturing concern know that its success depends upon the community's ability to attract other investors, to maintain safe and attractive streets and parks and high-quality education in its schools-in short, upon the community's whole social health. To say that a corporation's only goal is to make money would be to define the business corporation-for the first time in American or English law as I understand it-as a kind of shark that lives off the community rather than as an important agency in the construction, maintenance, and transformation of our shared lives. Of course the Draft as written does not say that making money should be a corporation's sole purpose (though such voices were heard in plenty at the meeting), but the form of the section does suggest that there is a structural opposition between "making money" on the one hand and "doing good" on the other. In my view, this opposition is false to our values and our experience, including our experience in business.

The corporation is and always has been a collective citizen. It serves not only its shareholders, but its bondholders and creditors of other kinds, as well as its employees and future employees, its suppliers and its customers. It has the proper aim not only of making money but of maintaining the conditions that make meaningful economic and social activity possible, for itself and for others. It is a citizen, and I believe it should be spoken of as having both the responsibilities and the benefits of that status. And to talk as if "economic" and "non-economic" objectives were mutually exclusive simply invites the extreme claim (which the Draft means to resist) that the "non-economic" objectives should be struck from the section, even in the permissive form in which they presently appear.

One might be tempted to dismiss this vision of business life as derived from a dead and romantic past in which community was face-to-face and business could afford to be less resolutely profit-maximizing than it must be today. And it is also true that there are other traditions of American business life than the one I describe. But I think the tradition I speak of is far more rational and sound, as well as more ethically appealing, than the tradition that makes investor interest its only goal. And I think that this is so not only for the small concern in the small community but for companies like Exxon or IBM as well; their capacity to "make money" is wholly dependent upon the continuation of a stable economic and social order, and the stability of that order is largely dependent upon its justice, or at least upon its perceived justice. Such corporations are in fact citizens 
of the world community and have as great a stake in and commitment to its health as any small business has in its small town. ${ }^{3}$

\section{II.}

Turning from the language of the section to that of the comments, one sees there an attempt to express a view something like my own, suggesting that the apparent conflict between selfish and public purposes expressed in the section itself will be to a large extent eliminated by a view of economic self-interest that takes into account the "long run" as well as the "short run." This view is in some sense similar to what I have been

3. For a statement of the traditional view, see The Business Roundtable "Statement on Corporate Responsibility" (1981):

Balancing the shareholder's expectations of maximum return against other priorities is one of the fundamental problems confronting corporate management. The shareholder must receive a good return but the legitimate concerns of other constituencies also must have the appropriate attention.

....

[E]conomic responsibility is by no means incompatible with other corporate responsibilities in society. In contemporary society all corporate responsibilities are so interrelated that they should not and cannot be separated.

Quoted and criticized in Bevis Longstreth, Defining the Corporate Objective and Implications for Philanthropy, S.E.C. Press Release, May 22, 1982.

4. Here is what is said in the comments:

$f$. The economic objective. In very general terms, the first clause of $\$ 2.01$ may be thought of as a broad injunction to maximize economic returns, while Subsections (a)-(c) make clear that certain kinds of conduct must or may be pursued whether or not they enhance such returns (that is, even if the conduct either yields no economic return or entails a net economic loss). In most cases, however, the kinds of conduct described in Subsections (a)-(c) could be pursued even under the first clause of $\S 2.01$. Such conduct will usually be consistent with economic self-interest, because the principle embodied in the first clause-that the objective of the corporation is to conduct business activities with a view to enhancing profit-does not mean that the objective of the corporation must be to realize profit in the short run. Indeed, the contrary is true: long-run profitability is at the core of the economic objective, although of course the fact that future profits are worth less than an equal amount of present profits must be weighed in any decision to forgo profit over the short run. Activity that entails a short-run cost to achieve an appropriately greater long-run profit is therefore not a departure from the economic objective, and an orientation toward lawful, ethical, and public-spirited activity will normally fall within this description. For comparable reasons, the economic objective does not imply that the corporation must extract the last penny of profit out of every transaction in which it is involved. Similarly, under normal circumstances the economic objective is met by focusing on the business in which the corporation is actually engaged.

...

h. Ethical considerations. It is sometimes argued that since adherence to ethical principles typically involves long-run financial benefits, the concept of the long run dissolves any apparent tension between financial and ethical considerations. Certainly, a long-run profit motive may often explain conduct that appears to be based on ethical grounds. . . . Furthermore, when ethical considerations enter into corporate decisions, they are usually mixed with, rather than opposed to, long-run profit considerations. Nevertheless, observation suggests that corporate decisions are not infrequently made on the basis of ethical considerations even when doing so does not enhance corporate profit or shareholder gain. Such behavior is not only appropriate, but desirable. A corporate manager is no less morally obliged than any other citizen to take ethical considerations into account, and it would be unwise social policy to preclude him from doing so.

This does not mean that corporate officials can properly take into account any ethical con- 
saying, but, aside from the fact that it never reaches the operative language of the section itself, the comment's way of putting the point seems to me almost as misleading as the opposition it is meant to address.

In the first place, to attempt to subsume everything-or almost everything-under the rubric of "making money," by saying that action in the general or public interest will help the corporation make money in the "long run," is to violate a basic rule of language and thought, that meaning resides in differences. "Making money" can have significance as a declared motive only if it is distinguished from some other motives, yet here it would collapse into them, and do so in a misleading way. What is the point of saying the corporation's goal is to enhance "corporate profit and shareholder gain" if what is meant by that is that the corporation should act as a responsible citizen in all aspects of life? In practice the effect of this language would be to cut the other way: to justify, or to require, placing short-term economic return first on the list.

Even more fundamentally, what we normally think of as economic reasoning is in fact incapable of functioning adequately over a long term, for it cannot reflect the importance of the social, cultural, and legal conditions and structures that make economic life as we know it possible. Economics is a game that takes place on conditions that do not figure in the game itself.

Consider, for example, this fact: The present value of $\$ 1,000,000$ in thirty years, assuming a $10 \%$ interest rate, is only $\$ 57,000$. But we all

sideration, no matter how idiosyncratic. Because such officials are dealing with other people's money, they normally will act properly in taking ethical principles into account only where those considerations are reasonably regarded as appropriate to the responsible conduct of business. One useful indicator of whether account may properly be taken of a given ethical consideration in a given case is whether doing so would be likely to violate the fair expectations of the corporation's shareholders taken as a group. This in turn is likely to depend on whether the consideration reflects a principle that would be widely recognized as appropriate to the responsible conduct of business by a significant portion of the community. In this connection it should be recognized that new principles may emerge over time, and a corporate official should therefore be permitted to take into account emerging ethical principles, reasonably regarded as relevant to the conduct of business, that have significant support although less-than-universal acceptance.

Draft, supra note $1, \S 2.01$, comments f \& h.

As I say at the outset, my difficulty with all of this is less with what I think the drafters are trying to say than with the consequences of the language they use. To the extent that the comments suggest that many, or most, "non-economic" interests can actually be taken into account by a "long-run" view of economic interest, they are subject to the criticism advanced in Section II of the text and also support the elimination of subsections (b) and (c) from the text of the Draft. To the extent that they suggest that some items are in direct conflict with economic self-interest, they perpetuate the opposition criticized above, and suggest no way in which that opposition can be addressed, let alone resolved.

The fact that subsections (b) and (c) are permissive rather than mandatory actually confuses matters more, for the one good argument for a narrow conomic-goals test is that it provides an external standard that limits a management's power to abuse its position. But the permissive provisions enable management to evade any such accountability, while at the same time devaluing all non-profit-making activity. Also, as the Draft shows, there is such flexibility in the meaning of profit maximization that it is doubtful whether such a standard would provide meaningful restraint in any case. 
know that some assets at the end of thirty years have an undiminished productive value: the properly managed farm; the piece of wilderness; even the well-built and well-managed building. The asset has of course been depreciated by the buyer, but this depreciation is artificial. The asset with a book value of zero may have a large real value, including in the market sense: the next 30 years of its use can be turned into a commodity, and bought and sold. But the largest part of its value-nearly everything beyond thirty years-cannot be included in, or reflected by, the exchange system.

Consider the point in connection with such resources as a wilderness area or a city park, such as Central Park in New York. Such an asset could be sold for present economically productive use at current prices; but by no stretch of the imagination could those prices reflect the true value of the asset over time to its present owners and beneficiaries, the public. What the exchange economy forgets, focused as it naturally is on present and short-term returns, is that the date in the future that it discounts so heavily will actually arrive and that when it does it will be as real, and as present, as the moment in which we now live. (One is reminded of the cigarette-smoker who thinks his day of reckoning will never come.)

Market economics fails to reflect the proper value not only of material wealth - the farm or river that produces commodities, the wilderness that offers us a unique experience of our place in the world-but, even more obviously, of what can be called social and cultural wealth as well. The habits of generosity, of law-abidingness, of willingness to participate responsibly in our public world-to work for others-which are a community's greatest assets cannot enter the market system at all. Or take education: The benefits of the schooling that our children receive, which will be of value not only to the family and friends but to all the neighbors of those children, will only just be beginning to bear fruit in thirty years. Under the market mode of thinking and valuing, our most important future assets are irrationally undervalued; correspondingly, our expenditures of money, time, and energy to maintain and improve those assets are overvalued.

This does not mean that the market has no proper role and place, but that it requires the existence of conditions that cannot be accounted for, or maintained, on its terms; these are assets that it should not be permitted to devour. Economics measures wealth not by the value of items exchanged but by margin or mark-up-by the difference between them. It is thus the natural impulse of the market to make a commodity out of everything, to ring down into present transactions all future wealth, all future happi- 
ness, and to do so on terms that discount future wealth, and overstate certain present expenditures, in a grossly inappropriate way.

Accordingly, I think the comments should not speak of "long-run" and "short-run" economic interest as though one were a version of, or continuous with, the other. "Economic motives," properly speaking, are those of short-term gain; for them the market and its methods of accounting may work well. But the cultural and social conditions necessary to that activity cannot be talked of in the same terms, because market accounting fails to reflect in a proper way the values-including ultimately economic values-that are at stake. For this plane of human activity, the economic model fails. To talk of the corporation as a citizen, by contrast, may invite us to integrate into a single view those elements of corporate life that the section places in false opposition to each other and that the comments to a large degree seek to collapse into one by a kind of talk about "long-run economic interest" that simply will not work.

In my view, the Draft is thus mistaken in several respects: in thinking of institutions in terms of materially defined ends or purposes; in thinking that "short-run" economic purposes can rationally be pursued without attention to the maintenance of the conditions that make the enterprise possible; and in thinking that this kind of attention can be adequately expressed by reference to a kind of "long-run" economic reasoning that will in fact not be able to reflect much of the value of those cultural and social conditions.

\section{III.}

I think the Draft makes another mistake as well, having to do with the nature of law and its relation to human action. The implicit ideology of subsection (a) is that the function of law is to regulate, by constraint and prohibition, human activity that is otherwise ungoverned except by principles of selfishness. This seems to me a paltry view both of law and of collective life. Actually, law always defines aspirations and values. It constitutes a set of relations and expectations. To claim that law has no such function is simply to establish aspirations of another and not very satisfactory kind. It is thus perfectly right-despite the language of the Draft and the remarks of the Reporter at the meeting-to expect that compliance with law should be not only a constraint on, but an objective of, corporate and other institutions (including the government itself) as well as of individuals. This is part of what is meant by citizenship.

At a more technical level, the language of the section impliedly adopts (again against much that is said in the comments) the mistaken view that the corporation "is" its shareholders, to whom alone fiduciary obligations extend, and who are related only by contract to the others who make up 
the corporation's world-employees, suppliers, customers, and the like. From a sociological point of view, this is simply wrong: The corporation is the center of a web of mutually-beneficial relations extending in many directions, and management has always known this. Good citizenship requires recognition of this plain social fact. The section's picture of the shareholder is wrong too. Instead of the hypothesized individual investor making long-term investment judgments based on the long-term merits of a business concern, the dominant shareholders at the level of national markets are enormous institutions who act in the interest of others who have, as citizens, every interest in the social health of the community as a whole. And even in strictly economic terms, the conduct of these institutions makes the image of the canny investor inappropriate, for such institutions often seek to diversify their investments to approximate a market index. To the extent that such institutions trade heavily in an attempt to increase short-term return, it is true that they deviate from the model of investing in the whole society, but the deviation is certainly not in the direction of long-term judgments about the soundness of the enterprises in which they invest.

\section{IV.}

The real evil at work here is the economic model of wealth, which takes into account only exchanges. This leads naturally to the monetization of value, to the conception of money income over time, and to a discount-rate of future value that is perhaps appropriate for an economic actor performing within a system, but which is wholly incapable of accounting for the true value to the world of wealth that is not actually reducible to the exchange economy: open spaces; clean air; good health; an educated population engaged in fulfilling work and leisure; the sense that we all have a stake in the quality of our common life, which alone can make streets safe and clean; and so on. That form of social and cultural wealth is the most valuable kind for all of us, "businessmen" and "public-interest groups" alike.

One implicit assumption of the section's talk about corporate "objectives" is that institutions are our creatures and can be made to our design against a background assumed to be stable. The designers can thus assume that economic objectives can be pursued in isolation from other aims and values. But if one thinks of one's own experience, including of "economic institutions," one sees that this is an extremely reduced vision of life. We cannot have the clearly itemized material objectives that such talk about institutions in terms of purposes assumes, because the context that gives them significance and priority is always shifting. We always operate under conditions of uncertainty. Our conduct produces consequences we 
can not foresee. Our motives are always imperfectly known, imperfectly stated, for they too properly shift as the basis of thought and action shifts. The "noneconomic background" that the Draft assumes to be stable, and which economics does not regard as a form of wealth (for it cannot be appropriated and exchanged), is actually not stable but perpetually remade; it is our most important form of wealth, which it is the first obligation of citizenship to maintain. ${ }^{.}$To isolate "economic goals" is to suggest a form of irrational parasitism; to attempt to bring everything under the umbrella of economic self-interest in the "long run" is to adopt a model of thought that in fact cannot deal with the long run, and this radically skews priorities in favor of short-run return.

What can serve as a sensible conception by which to organize corporate life? Not a conception of return, I believe, but a conception of intellectual and ethical attitude, of character. Our best goal is to be a certain kind of person, or company, or nation: the kind that can tolerate uncertainty, adapt to shifts in understanding, recognize the unknowability of the complex webs of causation in which we are caught, yet remain true to a sense of self and relation to others. Our best businessmen have always known this, for these are the qualities they have sought in their managers and leaders.

The real question is what language we should use to describe and constitute our business enterprises. The language of making money is wholly inadequate, even in the most conservative view-especially in the most conservative view - as to what goes on and should go on in the business world. In my view, the proper way to talk about this is to subordinate economic language to a language of citizenship, in a formula such as the following: "The business corporation should always endeavor to act as a responsible citizen in its economic and other activities." This language is, of course, very open indeed; but unlike the present Draft it should focus discussion on the character of the responsibilities and benefits of citizenship in our world, rather than on the false question whether the corporation's sole objective is to make money or whether it should also be required (or allowed) to "do good."

This is at least where I would begin, leaving it in the first instance to corporate actors and critics, and to the courts, to give meaning to this

5. Proper talk about economics in the real world should therefore always reflect an understanding of the culture within which the economic activity in question is to take place. To become fully responsible, economics should in fact become not merely "empirical," in the sense of moving from a tautological system to the measurement of exchange, but "cultural": a kind of "ethno-economics." If the economic analyst makes no attempt to understand the culture within which economic activity takes place, he or she becomes, wittingly or unwittingly, a proselytizer for a new total culture, based on the language and assumptions of economic theory-a culture with its own psychology, politics, and religion. 
standard as cases arise. I think the discourse that would arise on such a foundation would be clear enough to provide adequate guidance to private and public actors. They should certainly understand how to frame the essential questions for themselves. And this discussion should at least not collapse into the endless reassertions of a false dichotomy of the kind the present formulation invites.

Of course, this change in language would not provide automatic answers to particular questions; indeed, it would make many of them seem harder than they now do, for who is to decide what citizenship should mean, and how should they do so? But whatever we may pretend, the corporation is in fact a social institution as well as an economic one, and we should welcome, rather than reject, difficulties attendant upon the recognition of that fact. To do otherwise would be to choose one set of social consequences-those implicit in the "economic" model-without knowing what we were doing or why.

If more specificity were sought in the standard itself, it could be of two kinds. First, certain specified activities, such as partisan politics or campaign financing, could be restricted or eliminated, on the ground that the corporation's citizenship role ought not extend to electoral politics (for to do so would bias the electoral process even further in favor of the rich and politicize internal corporate life in an inappropriate way). Or one might specify the criteria of citizenship more fully, saying for example that the corporation should attempt to produce useful products and services, to provide adequate returns to investors and fair rewards to employees, to maintain its own health as a social and economic institution, and to do so with proper regard for the interests of other members of the larger community.

Whatever formulation is ultimately chosen, my main point remains this: that the language of economics is inadequate to what business corporations do and ought to do. This point extends far beyond corporation law. 


\section{The Yale Law Journal \\ Volume 94, Number 6, May 1985}

\author{
Mark E. Haddad \\ Editor-in-Chief \\ Beth S. Brinkmann \\ Julia E. Guttman \\ Peter D. Keisler \\ Sarah Korn \\ Robert A. Long \\ Note Editors
}

\author{
Amy L. Henrich \\ Managing Editor \\ Lynn A. Baker \\ Anita Bernstein \\ Ronald D. Lee \\ Howard M. Shapiro \\ William M. Treanor \\ Article \& Book Review Editors
}

Senior Editors

Pauline E. Calande

Sharon A. Hooper

Niki Kuckes

John R. Low-Beer

Robert S. Adelson

Thomas P. Arden

David M. Aronowitz

Ian Ayres

Stephanie E. Balcerzak

Julia E. Boaz

Patrick A. Broderick

James C. Buresh

Emily Buss

Evan H. Caminker

David K. Chan

Peter W. Chatfield

Kenneth Christman

Stephen M. Cutler

Patrick J. DeSouza

David R. Dow

Deborah D. Dupire

Peter R. Ezersky

Joan B. Gerbasi

Roberta G. Gordon
David A. Martland

Emily S. McMahon

John B. Sandage

Gene C. Schaerr

Paul Schwartz

\section{Editors}

Sarah B. Gordon

Donna J. Haggarty

Ruth E. Harlow

Jeffrey D. Hedlund

Rosemary Herbert

Rafael Hernández Mayoral Alan Hirsch

Dawn E. Johnsen

Kenneth C. Johnsen Julie B. Kaplan

Celia Goldman Kirsch Howard Kruse

Ronald J. Kuerbitz Marty Lederman William Levin

Christopher C. Magorian

Samuel A. Marcosson

David C. Marcus

David L. Meyer

John B. Morris, Jr.
Gene B. Sperling Peter P. Swire Stephen H. Willard Wendy A. Wolf

Business Manager: Pamela Standish

Editorial Assistant: Rosemary B. Carey

\section{Student Contributors to this Issue}

Peter R. Ezersky, Intra-Corporate Mail and Wire Fraud: Criminal Liability for Fiduciary Breach

Sarah B. Gordon, Indian Religious Freedom and Governmental Development of Public Lands

Amy L. Henrich, Preferential Treatment of Charities Under the Unemployment Insurance Laws

Emily S. McMahon, Chadha and the Nondelegation Doctrine: Defining a Restricted Legislative Veto

Stephen Hopkins Willard, A New Method of Calculating Copyright Liability for Cable Rebroadcasting of Distant Television Signals 